
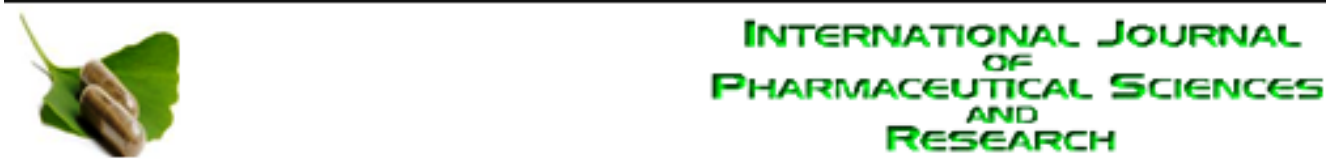

Received on 19 November, 2011; received in revised form 09 January, 2012; accepted 23 February, 2012

\title{
SYNTHESIS AND ANTIMICROBIAL ACTIVITY OF SOME CHALCONE DERIVATIVES AND THEIR COPPERCOMPLEXES
}

\section{P. M. Rachmale}

Dr. D.Y. Patil College of Pharmacy, Akurdi, Pune, Tal- Ahmedpur, Dist- Latur, Maharashtra, India

Keywords:

chalcone,

chalcone semicarbazone,

chalcone Isonicotyl hydrazone,

copper complexes,

antibacterial activity, antifungal activity

Correspondence to Author:

P. M. Rachmale

Dr. D.Y. Patil College of Pharmacy, Akurdi, Pune, Tal- Ahmedpur, Dist- Latur,

Maharashtra, India

\section{ABSTRACT}

In the present investigation, 4-chloro acetophenone on condensation with 2nitro benzaldehydes in methanolic $\mathrm{NaOH}$ solution yielded the corresponding chalcone. These chalcone were further reacted with Isonicotyl hydrazide and semicarbazide in ethanol which led to the formation of chalcone Isonicotyl hydrazone and chalcone semicarbazone derivatives respectively. The newly synthesized derivatives and there copper complexes were characterized on the basis of their chemical properties and spectroscopic data such as IR, NMR and UV. All newly synthesized compounds were evaluated for their antibacterial activities against $E$. coli and $S$. aureus also for antifungal activities against $P$. notatum.
INTRODUCTION: Benzelideneacetophenones belong to the class of naturally occurring pigments which are often referred to as "chalcones". The term was first coined by Kostanecki, who pioneered work in the synthesis of natural coloring compounds. An interesting feature of chalcones is that they serve as starting materials for another class of naturally occurring and widely distributed pigments called flavones ${ }^{1}$. Chalcones (fig. 1) have shown promising therapeutic efficacy for the management of human cancers.

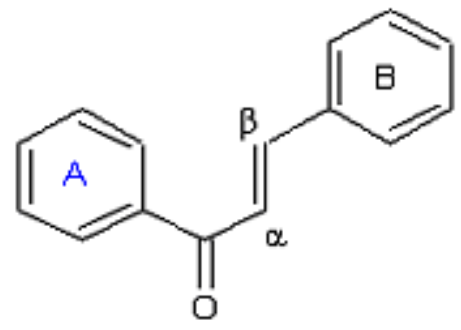

FIG. 1: CHALCONE

They are considered to be precursors of flavonoids and isoflavonoids which are abundant in edible plants. Chalcones are intermediates in the aurones synthesis of flavones.Chemically they are open- chain flavonoids in which the two aromatic rings are joined by a threecarbon alpha-beta- unsaturated carbonyl system (1,3diphenyl-2-propen-1-one) ${ }^{2}$.

Chalcones exhibit many pharmacological activities, including antileishmanial 3, antiinflammatory 4, 6, antimitotic 7 , antiinvasive ${ }^{8,} 9$, as well as antituberculosis ${ }^{10}$, antifungal ${ }^{11}$, cysteinyl leukotriene receptor-1 [CyLT1](LTD4) antagonist ${ }^{12}$, antimalarial ${ }^{13}$, 14, antiplasmodial, immunosupressive, cytotoxic, antitumor, and antioxidant properties ${ }^{15}$, anti fibrogenic activities and modulation of P-glycoproteinmediated multi-drug resistance ${ }^{16}$.

Recent studies have shown that chalcones inhibit cancer cell proliferation and are effective agents in vivo against skin carcinogenesis ${ }^{17,18}$. They induce apoptosis in various cell types, including breast cancers 19,20 . Several oxygenated chalcones, bischalcones, and some quinolinyl chalcone analogs reportedly show antimalarial activity ${ }^{21,22}$. Some chalcones demonstrate the ability to block voltage-dependent potassium channels ${ }^{23}$. 
Chalcone and their Derivatives: The Yakuchinones and their analogues are interesting due to their inhibitory effects on active oxygen, nematocidal activity, inhibition of lipid peroxidation and inhibition of acylCoX.

Iwata and co-workers have reported isomerisation of $\mathrm{E}$-chalcone to the $\mathrm{Z}$ form by exposing the methanolic solution of the chalcone to normal visible light ${ }^{31}$. Interestingly, the $\mathrm{Z}$ isomer showed more potent antitumor activity than the original $E$ form. Photoisomerisation of the predominant $E$ isomer to the $\mathrm{Z}$ isomer may cause change in biological activity and the ease with which the reaction occurs suggest that it is prudent to protect solution of chalcones from light.

Ducki et al., noted that the two bonds were positioned cis with respect to each other in several X-ray crystal structures of chalcones ${ }^{7}$. The s-cis conformer was more stable than the s-trans conformer by at least 3.9 $\mathrm{kJ} / \mathrm{mol}$. On the other hand, when a methyl group was introduced at the $C(\alpha)$ position, the disposition of the carbonyl and $C(\alpha)-C(\beta)$ double bonds altered to the trans orientation.

For these alpha-methyl chalcones, molecular mechanics calculations showed that the minimum energy contemners were s-trans and no s-cis conformation was evident within a $10 \mathrm{~kJ} / \mathrm{mol}$ range of the global energy minimum. The alpha -methyl group also caused significant loss of planarity between ring $A$ and the enone $\left(56-88^{\circ}\right)$. The $\alpha$-methylchalcones are found to have greater cytotoxic activity against a human leukemia cell line than the unsubstantiated analogues. Their unique geometrical features were cited as a possible factor contributing to the enhanced biological activity.

Hadjeri M. et al., conveniently substituted flavones, chalcones and quinolones are highly attractive derivatives due to their therapeutic potential. The substitution pattern of these compounds is crucial for their biological activity. Structure-activity relationship of flavone, indicates that: azaflavones are highly active molecules; the 5 and 7 positions are the most important; hydroxyls, methoxy and amino groups are the most beneficial.
Ronot, Xavier et al., reported that Chalcones (1, 3diphenylpropen- 1- ones) are naturally occurring compounds belonging to the flavonoid family and are largely investigated in various therapeutic area and especially as antitumor drugs. In the latter field, the literature survey indicates that effect on the cell cycle is one of the most important targets domains of chalcones.

Metal Complexes of Chalcone: Anjaneyulu et al., ${ }^{33}$ have suggested mechanism for the toxic action shown by metal chelates on the growth of the microorganism. The high toxic nature of the metal complexes towards viruses can be explained on the basis of the Chelation therapy. Structural studies on several metal chelates of beta-diketones and 2-hydroxycarbonyl compounds have been reviewed by Holm and O'Connor ${ }^{34}$.

Lense et al., ${ }^{35}$ as well as Palaniandavar and coworkers ${ }^{36}$ have reported that o-hydroxychalcones are much more reactive with metal ions than the ketones and aldehyders from which these are synthesized. The ohydroxycarbonyl compounds form a distinct category among chalcones which can form chelates with metal ions with low spin square-planar configuration, which do not easily form adducts and this has been attributed to the presence of extensive conjugation. Extensive conjugation was found to be responsible for the strong field nature of the ligands.

Rao and co-workers ${ }^{37}$ reported the synthesis and structural studies of complexes of Co (II), Ni (II), Cu (II), $\mathrm{Zn} \mathrm{(II)} \mathrm{and} \mathrm{Cd} \mathrm{(II)} \mathrm{with} \mathrm{substituted} \mathrm{chalcones.The}$ electronic spectral data suggest that all the Co(II) complexes and $\mathrm{Ni}(\mathrm{II})$ complex of 3-(2-pyridyl)-1-(2hydroxy phenyl)-2-propen-1-one (PHPO) complex are octahedral and all the $\mathrm{Cu}(\mathrm{II})$ and $\mathrm{Ni}$ (II) of 3-(1naphthyl)-1-(2- hydroxy phenyl)-2-propen-1-one (NHPO) and 3-(3, 4-dimethoxy phenyl)-1-(2- hydroxy phenyl)-2-propen-1-one (DMPHPO) complex are square-planar. The complex of $\mathrm{Zn}$ (II) and Cd (II) are tetrahedral. Devi and co-workers ${ }^{38}$ have studied the thermal properties of metal (II) complexes of chalcones. The thermal diffusivity of chalcone metal complexes is enhanced when compared to the parent ligands. So among metal complexes, thermal diffusivity increases with the increase in the free electron density of the metal ion coordination. 
Angadi et al., reported the Antimicrobial activity of $\mathrm{Cu}$ (II), Co (II) and Ni (II) complexes of chalcones. The antibacterial activity of chalcones and its complexes $\mathrm{Cu}$ (II), Co (II) and Ni (II) shows weak activity against E.coli and S.aureus when compared with standard streptomycin. The antifungal activity results revealed that the chalcones and its $\mathrm{Cu}$ (II), Co (II) and $\mathrm{Ni}$ (II), complexes have exhibited weak to good activity against A.niger and A.flavous. The chalcone and its $\mathrm{Cu}$ (II) and Co (II) complexes show weak activity when compared to the standard drug chlotrimazole.

Sharma and co-workers ${ }^{38}$ reported the Ruthenium (III) and Rhodium (III) Complexes with Chalcone Semicarbazones (2-hydroxychalcone) ${ }^{40}$. Mishra et al., have studied the Anti-HIV and Cytotoxic Activities of Ru (II)/Ru (III) mixed ligand complexes containing 2,6-(2'Benzimidazolyl)-pyridine and chalcone Ligands. Their interaction with aqueous buffered calf thymus DNA was measured and these results prompted additional screening for anti-HIV (human immunodeficiency virus) activity against DNA replication in $\mathrm{H} 9$ lymphocytes and cytotoxic activity against eight tumor cell lines. The most active compound was in the former assay have $\mathrm{EC}_{50}<0.1 \_\mu \mathrm{g} / \mathrm{Ml}$.

Nature of investigation: Chalcones continue to attract considerable scientific attention because of their association with a variety of biological activities. Only the cytotoxic and chemoprotective activities have been reviewed and even with this restriction, it is apparent that meaningful structure-activity correlations are difficult to establish for a specific activity. More importantly, the structural features of chalcones presence of a reactive enone moiety and its relative flexibility compared to other related natural products like flavonoids may predispose the template to interactions with diverse receptors and enzymes. The C6-C3-C6 motif is recognized as a "privileged structure" in drug design.

Goals of investigation: In the present study employed chalcone $(\mathrm{CL})$ moiety as the primary motif to achieve the inhibitory function which is appended with Semicarbazone and hydrazone pharmacophores as depicted in order to target intermediate kinases of the cell cycle. Conjugation of such ligands with copper is expected to endow antimicrobial property. The present study describes synthesis and characterisation of some chalcone analogues and their copper conjugation and evaluation of their antimicrobial activity.

MATERIALS AND METHODS: 2-Nitro benzaldehyde (Sisco,India), 4-Chloro actophenone (Sisco, India). Semicarbazide (Sisco, India), Thiosemicarbazide (Sisco, India), isonicotinyl hydrazides (Aldrich, USA)copper chloride dihydrate (Qualigens, India) and Zinc nitrate hexahydrate (Qualigens, India) were used as received. Solvents used in the synthesis of compounds were purified prior to their use according to literature protocols. Figure 2 provides the scheme of synthesis.

A. Synthesis of Chalcone: An ethanolic solution of 2Nitro benzaldehyde $(0.0035 \mathrm{~mol})$ was added to 4 Chloro acetophenone $(0.0035 \mathrm{~mol})$ with $0.5 \mathrm{ml}$ of methanolic $\mathrm{NaOH}$ (15mole). The reaction mixture was stirred for 30 min and monitored by TLC using Chloroform: methanol (9:1) as developing solvent. A yellow colored precipitate separated out at the end of the reaction which was filtered out and was washed with ether and dried under in vacuum over anhydrous $\mathrm{CaCl}_{2}$.

B. Synthesis of Schiff Base Ligands: The Schiff base ligands of above chalcone were prepared by reacting the respective chalcone and the respective semicarbazide (CLS), isonicotinyl hydrazide (CLI) in 1:1 stichiometric amounts in minimum amount of methanol with a few drops of glacial acetic acid. The reaction mixture was refluxed on the water bath for 6-8 hours. Completion of the reaction was monitored by TLC using chloroform: methanol (9:1) as the developing solvent. A dark green colored Product separated out when the mixture was allowed to cool. It was filtered out, washed with ether and dried in vacuum over anhydrous $\mathrm{CaCl}_{2}$.

C. Synthesis of Copper Complexes of Ligands: The general procedure involved interaction of the methanolic solutions of copper Sulphate and respective chalcone ligands in 1:1 metal: ligand stoichiometry and maintaining the reaction mixture at neutral $\mathrm{pH}$ at room temperature with constant stirring for $4 \mathrm{hrs}$. The precipitating metal conjugates were collected by filtration, washed with cold water and methanol. Finally, all compounds were dried under vacuum. 
<smiles>[R]NCC(=O)c1ccncc1</smiles>

FIG. 2: SCHEME OF SYNTHESIS

Year of experimentation: $\mathbf{2 0 1 0 - 1 1}$

Site: Dr. D.Y. Patil College of Pharmacy, Akurdi , Pune.
RESULTS AND DISCUSSION:

1. Physicochemical Characteristics:

TABLE 1: MELTING POINT AND R.F. VALUE OF CHALCONE SCHIFF BASE LIGANDS AND THEIR COPPER COMPLEXES.

\begin{tabular}{|c|c|c|c|c|c|c|}
\hline Sr. No & Name of Compound & Structure & MoL. Wt. & Colour & M.P. & R.F. Value \\
\hline 1 & CHALCONE & & 287.69 & $\begin{array}{c}\text { DARK } \\
\text { GREENISH }\end{array}$ & $119^{\circ} \mathrm{C}$ & 0.6 \\
\hline 2 & $\begin{array}{l}\text { CHALCONE SEMICA- } \\
\text { RBAZIDE }\end{array}$ & & 344.76 & PURPLE & $\begin{array}{l}130- \\
135^{\circ} \mathrm{C}\end{array}$ & 0.4 \\
\hline 3 & $\begin{array}{l}\text { CHALCONE SEMICA- } \\
\text { RBAZIDE } \\
\text { COPPER COMPLEX }\end{array}$ & & 602.44 & $\begin{array}{c}\text { DARK } \\
\text { GREENISH }\end{array}$ & Degradation & - \\
\hline 4 & $\begin{array}{l}\text { CHALCONE ISONIC- } \\
\text { OTYL HYDRAZIDE }\end{array}$ & & 406.82 & VIOLET & $140-145^{\circ} \mathrm{C}$ & 0.3 \\
\hline
\end{tabular}


CHALCONE ISONI-OTYL

5

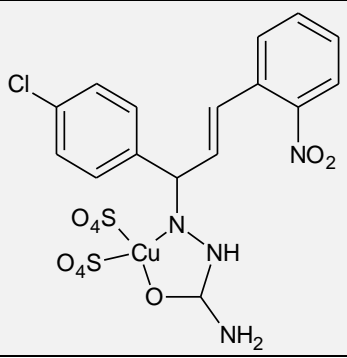

664.50
DARK PURPLE Degradation
2. Infrared Spectroscopy: The significant peaks in the IR spectra of the synthesized chalcone, ligands and their copper complexes with possible assignment are summarized in Table $\mathbf{2}$. The IR spectrum of the parent chalcone $(\mathrm{CL})$ exhibits a sharp intense band at $1720 / \mathrm{cm}$ due to carbonyl group. Upon Schiff base formation the free carbonyl stretch disappears accompanied by the appearance of $\mathrm{C}=\mathrm{N}$ stretching near $1570-1660 \mathrm{~cm}$ 1 which undergoes shift to low energy side upon metal coordination. The aromatic $\mathrm{C}=\mathrm{C}$ stretch can be observed in the region $1521-1591 \mathrm{~cm}^{-1}$ while the hydrazinic N-N stretch occurs in the range 1235$1251 \mathrm{~cm}^{-1}$. The appearance of metal-donor atom stretching vibrations such as $\vee \mathrm{M}-\mathrm{N}\left(440 \mathrm{~cm}^{-1}\right) \vee \mathrm{M}-$ $\mathrm{O}(520 \mathrm{~cm}-1)$ and confirm the presence of $\mathrm{N}$ and $\mathrm{O}$ donor atom sets for these compounds. All complexes exhibits a sharp band at $1330 \mathrm{~cm}^{-1}$ originating from v(Cu-SO4) vibration indicating the presence of sulphate ion in the metal coordination supporting the square planar geometry for the present complexes. Also, Nitro group exhibit sharp peak at $\mathrm{cm}^{-1}$ region.

TABLE 2: SIGNIFICANT PEAK IN IR SPECTRA OF CHALCONE SCHIFF BASE LIGANDS AND THEIR COPPER COMPLEXES

\begin{tabular}{ccccccc}
\hline \multirow{2}{*}{ Compound } & \multicolumn{7}{c}{ Probable Assignment (cm $\left.{ }^{-1}\right)$} \\
\cline { 2 - 7 } & $\mathbf{v}(\mathbf{N H 2}, \mathbf{N H})$ & $\mathbf{v}(\mathbf{C}=\mathbf{0})$ & $\mathbf{v}(\mathbf{C}=\mathbf{N})$ & $\mathbf{v}(\mathbf{C}=\mathbf{C})$ & $\mathbf{v}(\mathbf{N}-\mathbf{N})$ & $\mathbf{v}(\mathbf{M}-\mathbf{C l})$ \\
\hline CL & - & 1720 & - & 1591 & - & - \\
CLS & 3308,3248 & - & 1656 & 1591 & 1240 & - \\
CLSC & 3371,3268 & - & 1573 & 1535 & 1247 & 1270 \\
CLI & 3380 & - & 1654 & 1518 & 1251 & - \\
CLIC & 3416 & - & 1660 & 1523 & 1238 & 1159 \\
\hline
\end{tabular}

3. Electronic spectroscopy: The electronic spectra for all ligands and their copper complexes were recorded in DMSO solvent (table $\mathbf{3}$ ). The chalcone ligands are found to exhibit signals in the region 400-260 $\mathrm{nm}$ arising from $\mathrm{n} \rightarrow \pi$ and $\pi \rightarrow \pi$ intraligand transition respectively. The metal based $d-d$ transitions for the copper conjugates are observed in the region $600-700 \mathrm{~nm}$ in fig. 3 characteristics of square-planar geometry with $\mathrm{dx} 2-\mathrm{y} 2$ ground state.

TABLE 3: ELECTRONIC SPECTRAL ASSIGNMENTS FOR THE CHALCONE LIGANDS AND THEIR COPPER COMPLEXES.

\begin{tabular}{cccc}
\hline \multirow{2}{*}{ compounds } & \multicolumn{3}{c}{ Electronic spectral data (nm) } \\
\cline { 2 - 4 } & Intraligand & MLCT & d-d \\
\hline CL & 352 & - & - \\
CLSC & 325 & 400 & 670 \\
CLIC & 308 & 359 & 673 \\
\hline
\end{tabular}

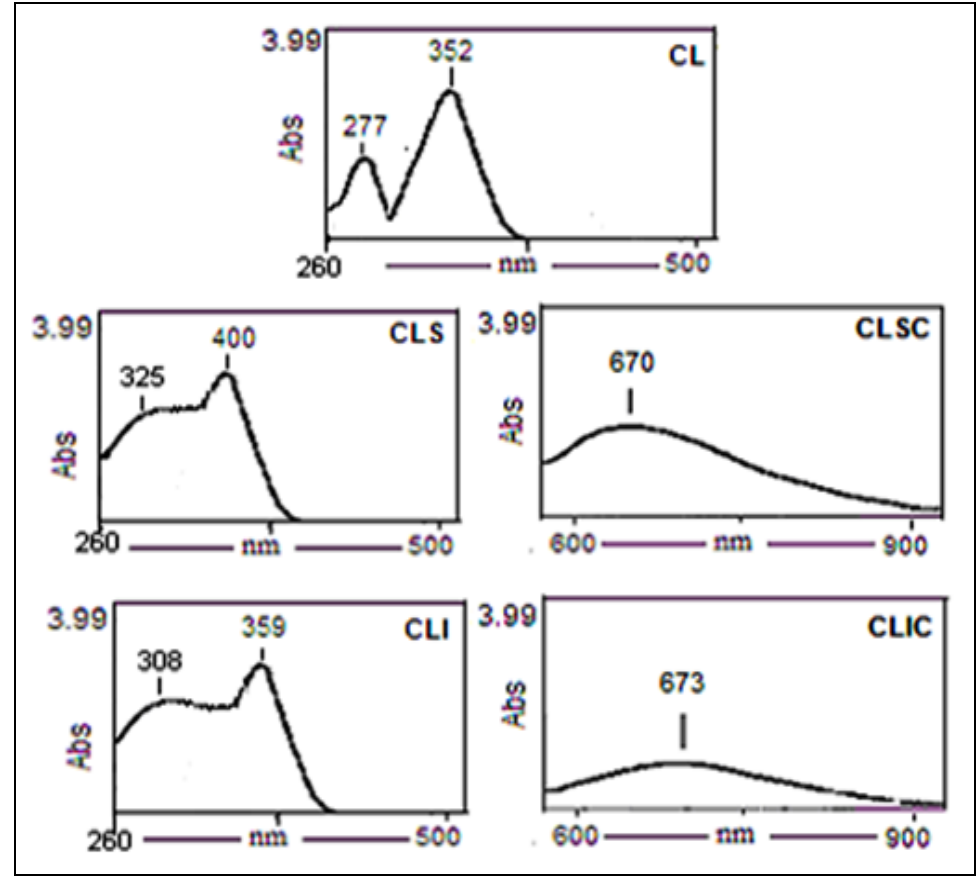

FIG 3. UV SPECTRAS OF SCHIFF BASE OF CHALCONE AND THEIR COPPER COMPLEX 
4. 'H-NMR Spectroscopy: NMR spectroscopy enables us to record differences in magnetic nuclei present and to deduce in the large measure about the position of these nuclei within molecule. the proton NMR spectrum enables us to know different chemical and magnetic enviorments corresponding to protons in a molecules. The synthesized compound were subjected to ${ }^{1} \mathrm{H}$-NMRstudies on varian FT-NMR spectrophotometer (300 mhz).

In the $\mathrm{CL}$ (fig. 4), parent chalcone aromatic $\mathrm{CH}$-group of ring A exhibits signal at $\delta 7.45-7.48$ ppm and $\delta 7.45-$ 7.77 ppmrespectively. In case of Schiff base ligand's CLS (fig. 5) , CLI (fig. 6) this signal is shifted to $\delta 7.29$ $7.30 \mathrm{ppm}$ and $\delta$ 7.58-7.60 ppm The signal corespond's to $\mathrm{NH}$ group appear's at $\delta 6.7 \mathrm{ppm}$ while $\mathrm{NH} 2$ group appear's at $\delta 6.0 \mathrm{ppm}$ in CLS but in CLI pyridyl proton appear's at $\delta 7.96 \mathrm{ppm}$ and $\delta 9.08 \mathrm{ppm}$ in singlet form. Ethylene proton appear's in all ligand's at $\delta 5.62 \mathrm{pm}$ and $\delta 7.0 \mathrm{ppm}$ in doublet form and in $\mathrm{CL}$ at $\delta 5.78 \mathrm{ppm}$ and $\delta 7.9$ ppmin the doublet form.

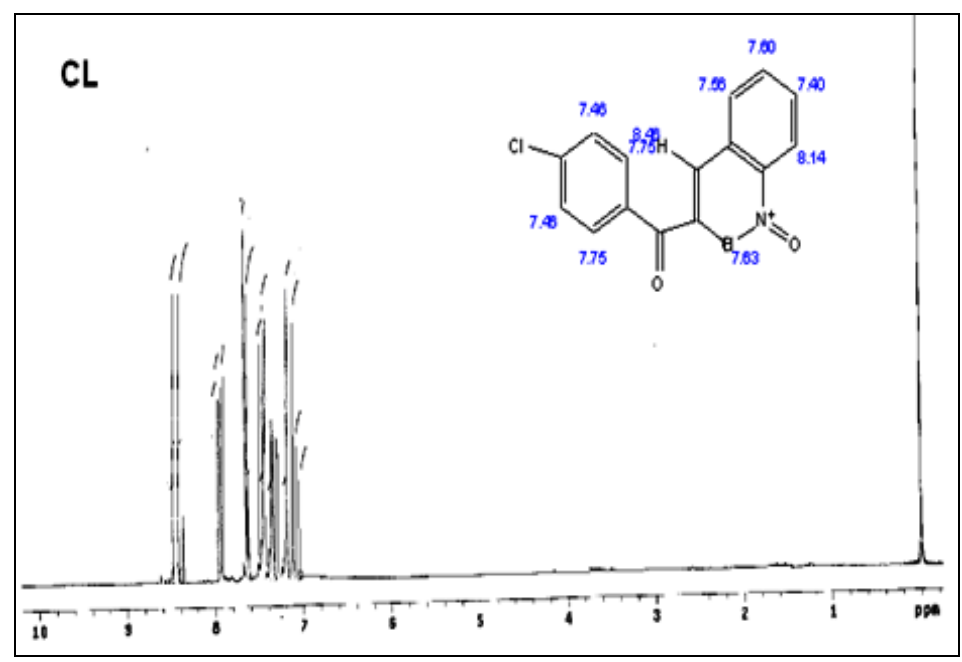

FIG. 4: NMR OF CHALCONE

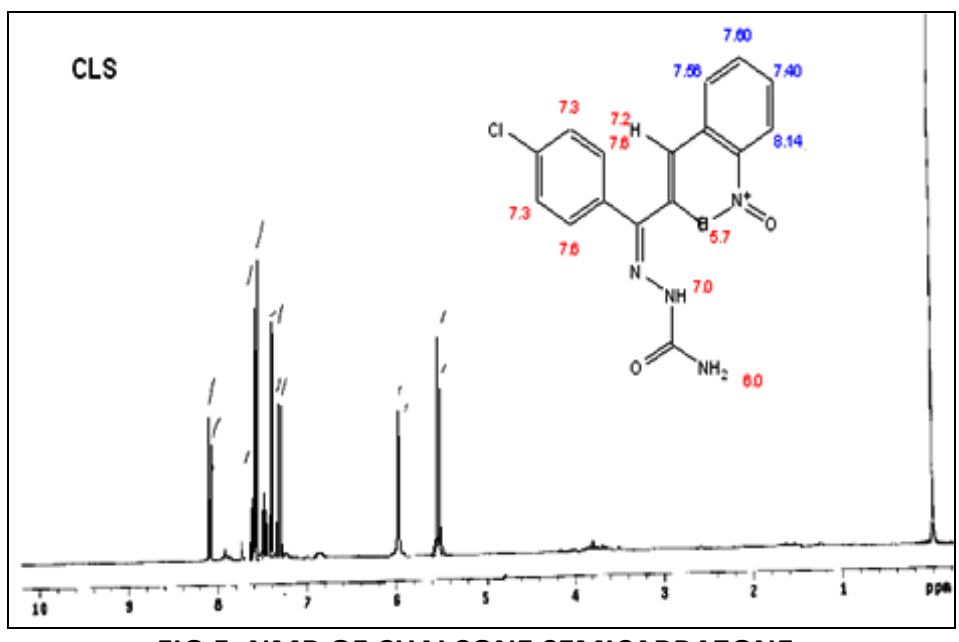

FIG.5: NMR OF CHALCONE SEMICARBAZONE

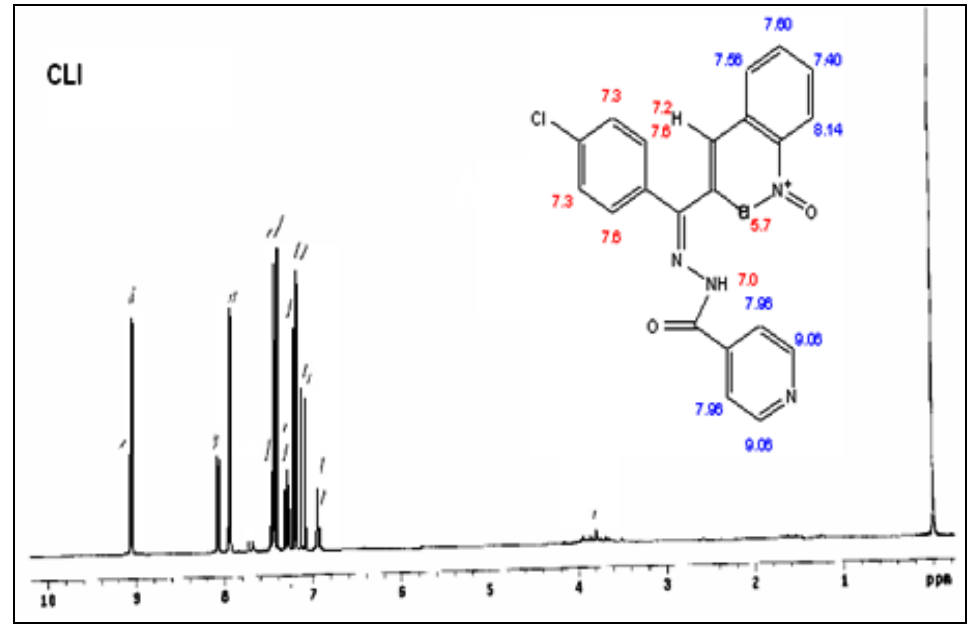

FIG. 6: NMR OF CHALCONE ISONICOTYL HYDRAZONE

5. Antimicrobial activity: The antimicrobial activity of chalcone and its ligands studied by cup-plate method (table 5). In this method, agar is melted and cooled at $45^{\circ} \mathrm{C}$, inoculated with the test microorganisms and poured into a sterile petriplate. In the cup-plate method, inoculated agar has solidified, holes about $5 \mathrm{~mm}$ in diameter are cut in the medium with a sterile cork borer. The antimicrobial agent is directly placed in the holes and plates are incubated at $37^{\circ} \mathrm{C}$ for $48 \mathrm{hrs}$. and measure the zone of inhibition.

\section{Procedure:}

a) Preparation the Stock Solution of $1000 \mu \mathrm{M} / \mathrm{ml}$ : (chalcone- 2.88mg in $10 \mathrm{ml}$ DMSO.) (chalcone semicarbazide- $3.45 \mathrm{mg}$ in $10 \mathrm{ml}$ DMSO.) (chalcone semicarbazide Cu-complex- $6.02 \mathrm{mg}$ in $10 \mathrm{ml}$ DMSO) (chalcone Isonicotyl Hydrazide- $4.06 \mathrm{mg}$ in $10 \mathrm{ml}$ DMSO.) (chalcone Isonicotyl Hydrazide Cu-complex - 4.06mg in $10 \mathrm{ml}$ DMSO.)

b) Preperation of Standard Solution: By dissolving $18.33 \mathrm{mg}$ penicillin in $10 \mathrm{ml}$ DMSO to prepare 1000 $\mu \mathrm{M} / \mathrm{ml}$. Further dilution done using DMSO. prepare Nutrient Agar Media (28gm Nutrient Agar powder in $1000 \mathrm{ml}$ distilled water)and sterilized it. Prepare bacterial suspension in distilled water and spread on petriplate using spreader. Add $0.5 \mathrm{ml}$ test solution in each bore. Incubate all petriplates at $37^{\circ} \mathrm{C}$ for $48 \mathrm{hrs}$. Measure the zone of inhibition.

\section{S. aureus - Staphylococcus aureus \\ E. coli - Escherichia coli \\ $P$. notatum - Penicillium notatum}




\begin{tabular}{|c|c|c|c|c|c|c|}
\hline \multirow{3}{*}{ Compound } & \multirow{3}{*}{ Micro-organism } & \multicolumn{5}{|c|}{ Dilution $(\mu \mathrm{M} / \mathrm{ml})$} \\
\hline & & 100 & 150 & 200 & 250 & 300 \\
\hline & & \multicolumn{5}{|c|}{$\mathrm{ZOI}$ in $\mathrm{mm}$} \\
\hline \multirow{3}{*}{ Standard } & S.aureus & 7 & 8 & 8.6 & 9 & 10 \\
\hline & E. coli & 7.1 & 7.2 & 7.4 & 8.6 & 9.2 \\
\hline & P. notatum & 9.4 & 10.8 & 11.2 & 12.4 & 13.6 \\
\hline \multirow{3}{*}{$\mathrm{CL}$} & S. aureus & 9.4 & 15.6 & 17.2 & 17.4 & 17.7 \\
\hline & E. coli & 7.2 & 7.4 & 8.4 & 9.6 & 10 \\
\hline & P. notatum & 11.4 & 13.8 & 15.2 & 17.4 & 21.6 \\
\hline \multirow{3}{*}{ CLS } & S. aureus & 9.2 & 15.6 & 11.6 & 12.4 & 10.6 \\
\hline & E. coli & 5.6 & 5.8 & 6.2 & 6.8 & 7.2 \\
\hline & P. notatum & 11.6 & 13.4 & 18.4 & 20.6 & 13.8 \\
\hline \multirow{3}{*}{ CLSC } & S. aureus & 7 & 7.4 & 8 & 8.6 & 8 \\
\hline & E. coli & 7 & 9 & 10 & 11 & 11.4 \\
\hline & P. notatum & 6.6 & 8 & 8.4 & 14 & 15 \\
\hline \multirow{3}{*}{ CLI } & S. aureus & 9 & 10 & 13 & 13.4 & 14 \\
\hline & E. coli & 13 & 17 & 15 & 16.4 & 16.8 \\
\hline & P. notatum & 7 & 8 & 9 & 11 & 17 \\
\hline \multirow{3}{*}{ CLIC } & S. aureus & 7 & 8 & 9.4 & 15 & 23 \\
\hline & E. coli & 11 & 12 & 13.2 & 11 & 7 \\
\hline & P. notatum & 15 & 16 & 17.2 & 17.7 & 18 \\
\hline
\end{tabular}

TEST COMPOUND
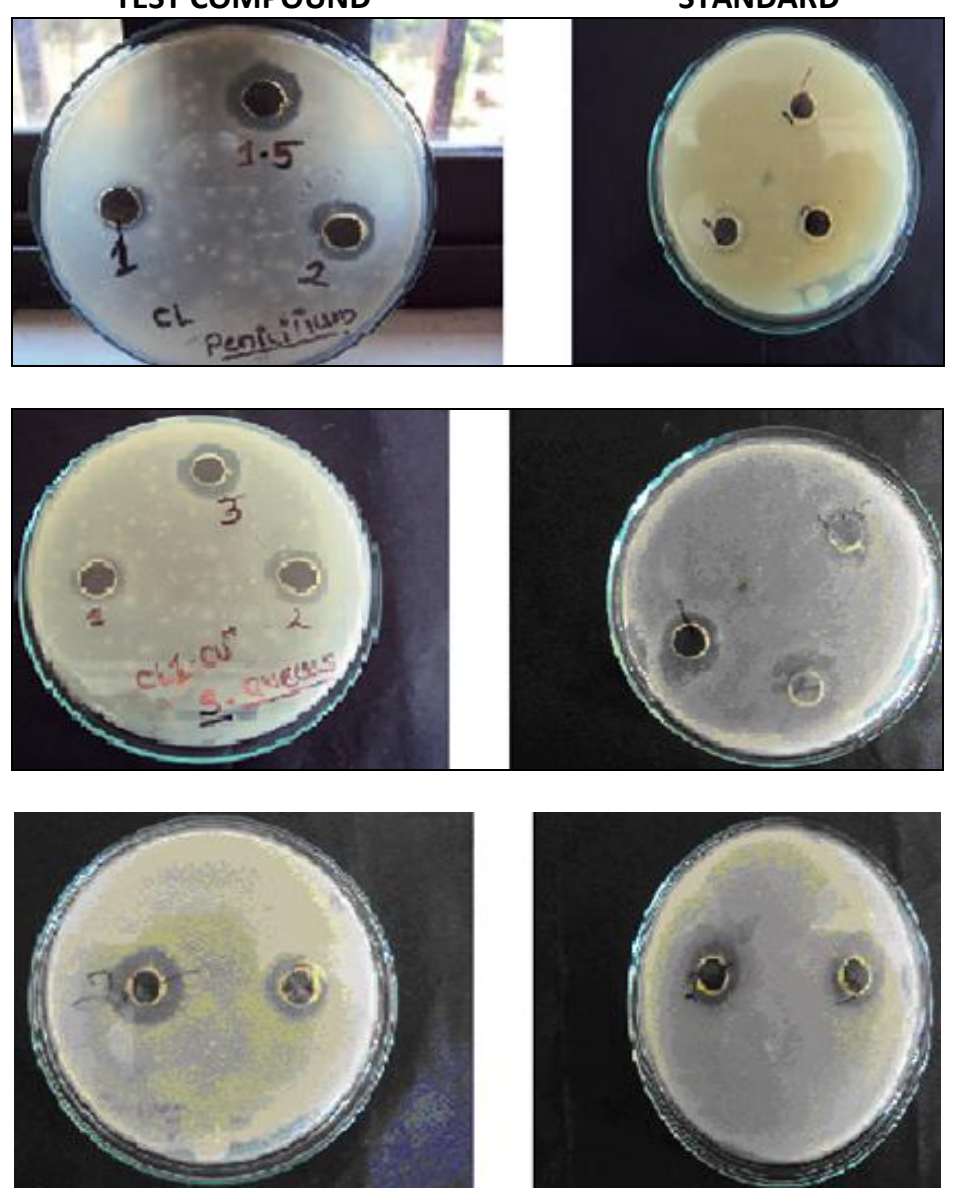

CONCLUSION: The present work represents a novel series of chalcone Schiff base derivatives and their copper complexes exhibiting significant antimicrobial activity towards various microbial strain. In this context semicarbazone pharmacophore is a good choice for designing such agents. Metal chelation seems to be helpful in enhancing the antimicrobial activity .In antimicrobial activity concentration increases the zone of inhibition also increases.chalcone $(C L=21.6 \mathrm{~mm}$ at $300 \mu \mathrm{M} / \mathrm{ml}$ ) and chalcone semicarbazone derivative (CLS=20.6mm at $250 \mu \mathrm{M} / \mathrm{ml}$ ) exhibiting potent antifungal activity towards $\mathrm{P}$. notatum as compared to standard ( standard $=12.4 \mathrm{~mm}$ at $250 \mu \mathrm{M} / \mathrm{ml}$ ) . As well as copper complex of cxhalcone isonicotyl hydrazone derivative ( $\mathrm{CLIC}=23 \mathrm{~mm}$ at $300 \mu \mathrm{M} / \mathrm{ml}$ ) exhibit promising antibacterial activity towords $\mathrm{S}$. aureus.This strategy can be refined further for optimization.

\section{REFERENCES:}

1. Yerra Koteswara Rao, Shih-Hua Fang and Yew-Min Tzeng, Bioorganic \& Medicinal chemistry volume- 12 . 2004; 26792686.

2. Kostanecki,S.V.,and Tambor A.V. Journal of Chemistry-volume32. 1921-1899.

3. Nielsen S.F. , Christensen S.B., Cruciani A., Kharazmi,A., Liljefros,T,J.. Medicinal chemistry volume -41,1998, 4819-4832.

4. Ko H.H.,Tsao L.T.,Yu K.L., Liu,C.T., Wang,J.P., Lin,C.N . Bioorganic \& Medicinal chemistry volume-11,2003; 105-111.

5. Matsuda H., Morikawa T., Ando S.,Iwao T., Masayuki Y. Bioorganic \& Medicinal chemistry volume- 11,2003; 19952000.

6. Herencia F., Ferrandiz M.L., Ubeda A., Dominguez J.N., Charris J.E., Lobo G.M., Alcaraz M.J. Bioorganic \& Medicinal chemistry Letterature-8,1998; 1169-1174.

7. Ducki S., Forrest R., Hadfield J. A., Kendall A., Lawrence N. J., Mcgown A.T., Rennison D. Bioorganic \& Medicinal chemistry Letterature-8, 1998; 1051-1056.

8. Parmer V.S., Sharma N. K., Husain M., Watterson A. C., Kumar J., Samuelson L.A., Ashok L. C., Prasad A. K., Kumar A, Malhotra S., Kumar N., Jha A., Singh A., Singh I., Himanshu V. A., Shakil N. 
A., Trikha S., Mukherjee S., Sharma S. K., Singh S. K., Kumar A., Jha H. N., Olsen C. E., Stove C. P., Bracke M. E., Mareel M. M. Bioorganic \& Medicinal chemistry volume- 11,2003; 913- 929.

9. Mukherjee S., Kumar V., Prasad A. K., Raj H. G., Bracke M. E., Olsen C. E., Jain S.C., Parmar V. S. Bioorganic \& Medicinal chemistry volume- 9, 2001; 337-345.

10. Lin Y. M., Zhou Y., Flavin M. T., Zhou L. M., Nie W., Chen F. C. Bioorganic \& Medicinal chemistry volume- 10, 2002; 27952802.

11. Lopez S. N., Castelli M. V., Zacchino S. A., Domlnguez J. N., Lobo G., Jaime C.C., Cortes J. C. G., Ribas J. C., Devia C., Ana M. R., Ricardo D. E. Bioorganic \& Medicinal chemistry volume9,2001; 1999-2013.

12. Zwaagstra M. E., Timmerman H., Tamura M., Tohma T., Wada Y., Onogi K., Zhang M.Q.J. Med. Chem. 40 ,1997; 1075-1089.

13. Li R., Kenyon G. L., Cohen F., Chen X., Gong B., Dominguez J. N., vidson.E., Kurzban G., Millar R. E., Nuzum E. O., Rosenthal, P. J., Mckerrow Journal of Medicinal chemistry. 381995; 5031-5037.

14. Liu M., Wilairat P., Go M. L., journal of Medicinal chemistry volume- 44, 2001; 4443-4452.

15. Go M. L., Wu X., Liu X. L. Current Medicinal chemistry volume12 2005; 483-499.

16. Bois F., Boumendjel A., Mariotte A., Conseil G., Di Petro A. Bioorganic \& Medicinal chemistry volume- 7 .1999; 2691-2695.

17. Statomi Y. International Journal of Cancer- 55, 1993; 506-514.

18. Yamaoto S., Aizu E., Jian H., Nakadate T., Kiyoto I., Wang J. C., Research on Carcinogenesis-12, 1991; 317-323.

19. Claude-Alain C., Jean-Chritophe L., Patrick T., Christelle P., Gerard H., Albert-Jose C., Jean-Luc D. Anticancer Research- 21, 2001; 3949-3956.

20. Ezio B., Salvatore M., Franco D. M. PCT International Appl. 1998/18 pp.

21. Liu M., Wilairat P., Croft S. L., Lay-Choo A., Go M. L. Bioorganic \& Medicinal chemistry volume- 11,$2003 ; 2729-2738$.

22. Dominguez J. N., Charris J.E., Lobo G., Gamboa-Dominguez M., Moreno M., Riggione F., Sanchez E., Olson J., Rosenthal P. J. European Journal of Medicinal chemistry volume- 36, 2001; 555-560.

23. Yarishkin O.V., et al, Bioorganic \& Medicinal chemistry Letterature-18, 2008; 137-140.
24. Hideo Yamasaki, Yasuko Sakihama, and Norikatsu \kehara, Plant Physiology-115, 1997; 1405-1 412.

25. Mauricio Cabrera, Macarena Simoens, Gabriela Falchi , Laura Lavaggi , Oscar Eduardo E., Castellano. Bioorganic \& Medicinal chemistry volume- 15,2007 ; 3356-3367.

26. Bors W., Heller W., Michel C., Saran M. Methods Enzymol -186; 1990 343- 355

27. Dinkova-Kostova A.T., Abeygunawardana C., Talalay P., Journal of Medicinal chemistry volume- 41, 1998; 5287.

28. Tanaka T., Makita H. , Kawabata K., Mori H., Kakumoto M., Satoh K., Hara A., Sumida T., Ogawa H., Carcinogenesis-18, 1997; 957.

29. Xia Y., Yang Z. Y., Xia P., Bastow K. F., Nakanishi Y., Lee K. H. Bioorganic \& Medicinal chemistry literature volume- 10, 2000; 699.

30. Pati H. N., Holt H. L., LeBlanc R., Dickson J., Stewart M., Brown T. Bioorganic \& Medicinal chemistry volume-14, 2005; 19.

31. Dimmock J. R., Jha A., Zello G. A., Allen T. M., Santos C. L., Balzarini J., De Clercq E., Manavathu E. K., Stables J. P. Pharmazie-58, 2003; 227.

32. Xiaoling Liu and Mei-Lin Go, Bioorganic \& Medicinal chemistry volume- 15,2007 ; 7021-7034.

33. Fenwick G.R., Lutomski J., Nieman C., Food Chemistry- 38, 1990; 119-143.

34. Sheng L.H., Traditional Chinese Medicine and immunity, Guangdong scientlfic Publishing House, Guangzhou, People's Republic of China, 1982 ; 41-49.

35. Wegener J.W., Nawrath H., European Journal of Pharmacology326, 1997; 37-44.

36. Kang D.G., Lee A.S.,Woo W.H., Kim Y.C., Sohn E.j., MoonL.G. Biological Pharmacology Bulletin- 27, 2004; 366-370.

37. Elisabeth Bertl, Hans Becker, Theophil Eicher, Christian Herhaus, Govind Kapadia, Helmut Bartsch , Clarissa Gerhauser. Biochemical and Biophysical Research Communications -325, $2004 ; 287-295$.

38. Albini A., Dell'Eva R., Vene R., Ferrari N., Buhler D.R., Noonan D.M., Fassina G.. FASEB Journal-20, 2006; 20527-20529.

39. Dell'Eva R., Ambrosini C., Vannini N., Piaggio G., Albini A., Ferrari N. Cancer -110, 2007; 2007-2011.

40. Nakadate T., Aizu E., Yamamoto S., Kato R. Prostaglandins-30, 1985; 357. 